\title{
AHP Evaluation Study of the Land Use Intensity on Regulatory Plan Management Unit Level of the Small and Medium-Sized City in Guanzhong Area
}

\author{
Hou Quanhua ${ }^{1, *}$ Xu Fang ${ }^{2}$ and Feng Ting ${ }^{1}$ \\ ${ }^{I}$ The Architecture School of Chang'an University, Shaanxi Xi'an 710061, ${ }^{2}$ Uban Planning \& Architectural Design \\ Institute Of Hunan City University, Hunan Yiyang 413049
}

\begin{abstract}
The paper, by taking Pucheng, a typical small and medium-sized city in Guanzhong area, as an example, conducts a study on the scientific determination of land use intensity zoning at the regulatory management unit level by reference to the analytic hierarchy process (AHP) model. Meanwhile, this paper constructs evaluation methods and systems of land use intensity zoning at such level. This evaluation system can be summarized as "four levels and two steps". "Four levels" refer to the total target level (T), total factor level (A), sub factors level (B) and index level (C) respectively. Two steps are first classifying the basic factors through weighing the most underlying factors (namely, the index level) and second calculating the weight of each unit in terms of each factor level to get the weight of each unit under the dominant influence factors and minor influence factors, and establish basic intensity and modifying zones so as to finally determine the ultimate reasonable zoning of land use.
\end{abstract}

Keywords: Evaluation system of AHP, land use intensity zoning, regulatory plan management unit, Shaanxi Pucheng, small and medium-sized cities in Guanzhong area.

\section{THE FEATURES OF THE SMALL AND MEDIUM- SIZED CITIES IN GUANZHONG AREA, AND THE SYSTEM OF DRAFTING THEIR REGULATORY PLAN}

The control of urban land use intensity is the hot topic and focus in current research of urban planning, which plays an important role in the development process of urban planning, especially to the regulatory plan ("regulatory plan" for short in the following). The characteristics and legal status of drafting regulatory plan, and its functions in the urban planning management are becoming increasingly important. In recent years, with the implementation of 《Approval Measures on Drafting Regulatory Plan of Cities and Towns》, the work of drafting "the full coverage" of regulatory plan is vigorously promoted all over the country, and some cities, such as Beijing, Shanghai, Guangzhou, Wuhan, Nanjing, Jinan and so on, have put forward some new methods on the regulatory plan about "total constraints---hierarchical control---zoning equilibrium", which adapted to the city's own characteristics (Fig. 1). But at present, such methods are mainly aimed at for large and medium-sized cities. The researches on urban use intensity zoning of small and mediumsized cities are still little, especially to that of Guanzhong area. Secondly, the traditional methods of drafting regulatory plan can no longer meet the requirements of the control of urban use intensity. The control of a single block in the overall strength and the rationality can't control the whole land use intensity. As a result, the regulatory plan presented the "out of control" state, with the whole city being lack of rationality. Thirdly, in order to avoid the crisis of losing city characteristic, it is necessary for the control of urban construction intensity to carry out protective development at the city's features, especially to the small and medium-sized cities in Guanzhong area, which have strong historical and cultural characteristics. Under this situation, it happens to provide a research platform for innovation of planning, thus giving regulatory plan a more important responsibility [2-4].

Land development intensity as the core control content in the regulatory plan phase, the scientific rationality of whose indices has always been a hot topic in academic research. The small and medium-sized cities in Guanzhong area divided regulatory plan into three spatial levels as "area - management unit - block", among which, floor area ratio, the main index of land use intensity mainly refers to different connotations (Table 1). To establish division of the regulatory plan's unit of the small and medium-sized cities in Guanzhong area, and to determine of the reference floor area ratio of all types of land use within the unit rate can also provide some reference for the next step of drafting the regulatory plan [5-7].

During the process of hierarchical regulatory plan of the small and medium-sized cities in Guanzhong area, while grasping the overall total control, this article explore analysis and research of the intensity of land use management on the level of management unit, establish levels of zoning, get the reference floor area ratio of each unit, and thus guiding the development of the more detailed block-level land. Therefore, the research of land use intensity partition control on 


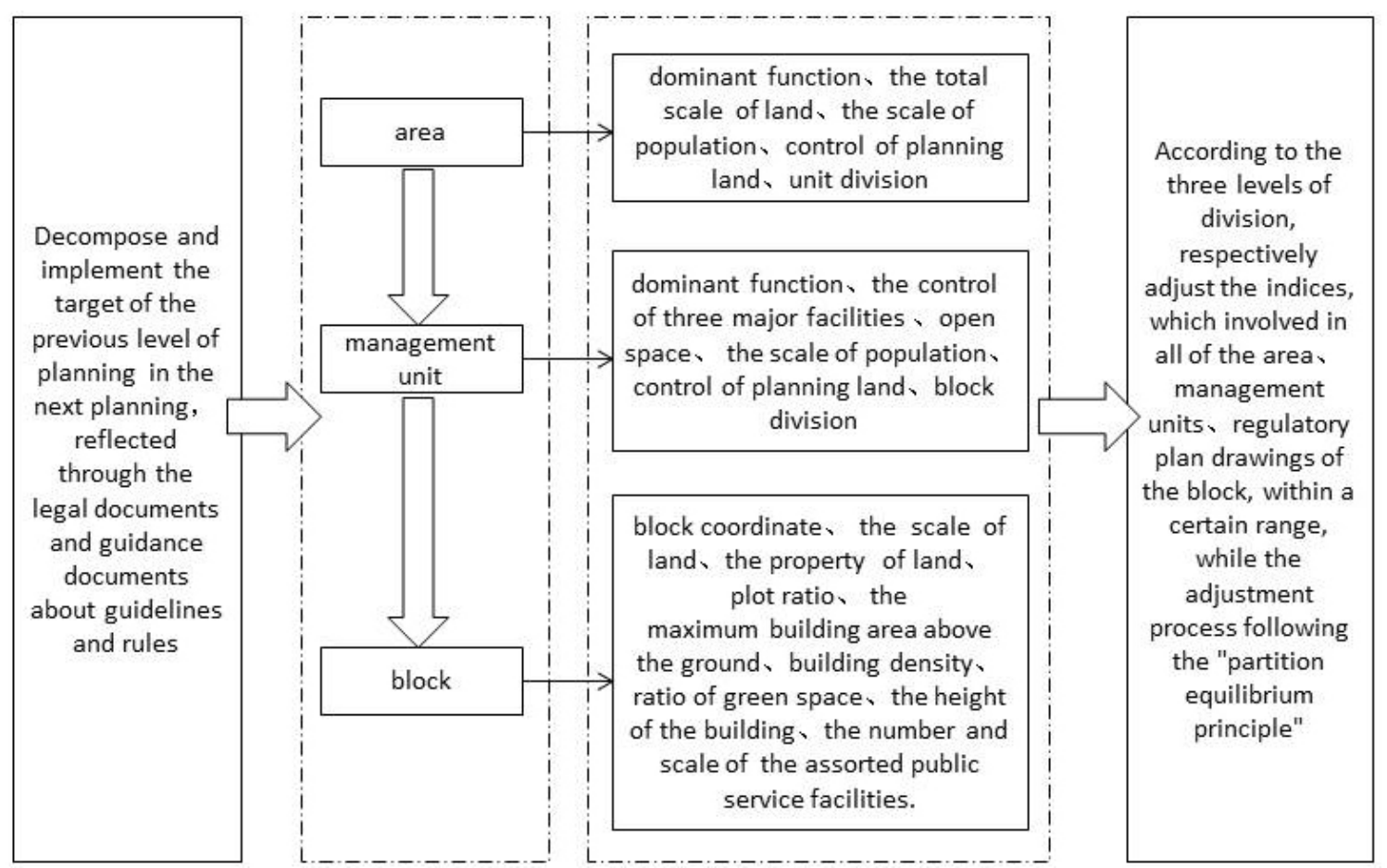

Fig. (1). Schematic diagram of hierarchical regulatory.

Table 1. The list of three levels indices of the regulatory plan floor area ratio.

Source: Arranged by the author, according to the relevant documentation

\begin{tabular}{|c|c|c|c|}
\hline \multirow{2}{*}{ Spatial Levels } & \multicolumn{2}{|c|}{ The Main Index of Land Use Intensity } & The Connotation of the Index \\
\hline \hline \multirow{2}{*}{ area } & \multirow{3}{*}{ the regulatory floor area ratio } & the average floor area ratio & description of the average land use intensity of the area \\
\cline { 3 - 4 } & & the reference floor area ratio & description of the average land use intensity of the unit \\
\cline { 3 - 4 } management unit & floor area ratio & description of the average land use intensity of the block \\
\hline block & &
\end{tabular}

management unit level becomes very meaningful. Taking Shaanxi Pucheng as the research object, the article carries on zoning research about the city construction intensity based on "management unit level" [8].

\section{EVALUATION METHODS FOR LAND USE IN- TENSITY ZONING OF AHP APPLIED TO THE MANAGEMENT UNIT LEVEL}

\subsection{The Methods and Principles to Construct an Evalua- tion System of Using Intensity Zoning by AHP}

AHP (Analytic Hierarchy Process), proposed by professor T.L. Saaty, an USA operational research expert, in the late 1970 's, is considered to be a decision method which is scientific and reasonable in theory while simple and convenient in application, and can also makes a comprehensive analysis of the qualitative and quantitative issues, therefore it is widely used in research and development in the evaluation work. The basic ideas of AHP are: First of all, to establish an orderly hierarchical system, according to the nature of the question and the overall goal that is required to achieve. And then evaluates each two of the relevant factors in the system, through a comprehensive calculation and treatment to the results of this kind of comparison and evaluation, eventually summarizes the systematic analysis as a problem about the determination of the comparatively importance weights or the sequence of the comparatively pros and cons, the lowest (decision objects, programs, measures, etc.), with respect to the highest level (overall objective). AHP contains two basic parts: one is to establish a hierarchical structure, concretely including the work of determining the target layer, criterion layer, program layer, and constructing the hierarchical structure. The second is to determine the weights of evaluation levels, concretely including work of constructing judgment matrix, sequencing the importance of calculation of the single criteria, the synthesis weight of the calculation levels.

Using AHP to construct evaluation methods and evaluation systems of land use intensity zoning on the regulatory management unit level, firstly we need to make a reasonable amount allocation of land use intensity in center city, which defined to the overall urban planning, regard building classifications of center city (unit level) intensity zoning as total 


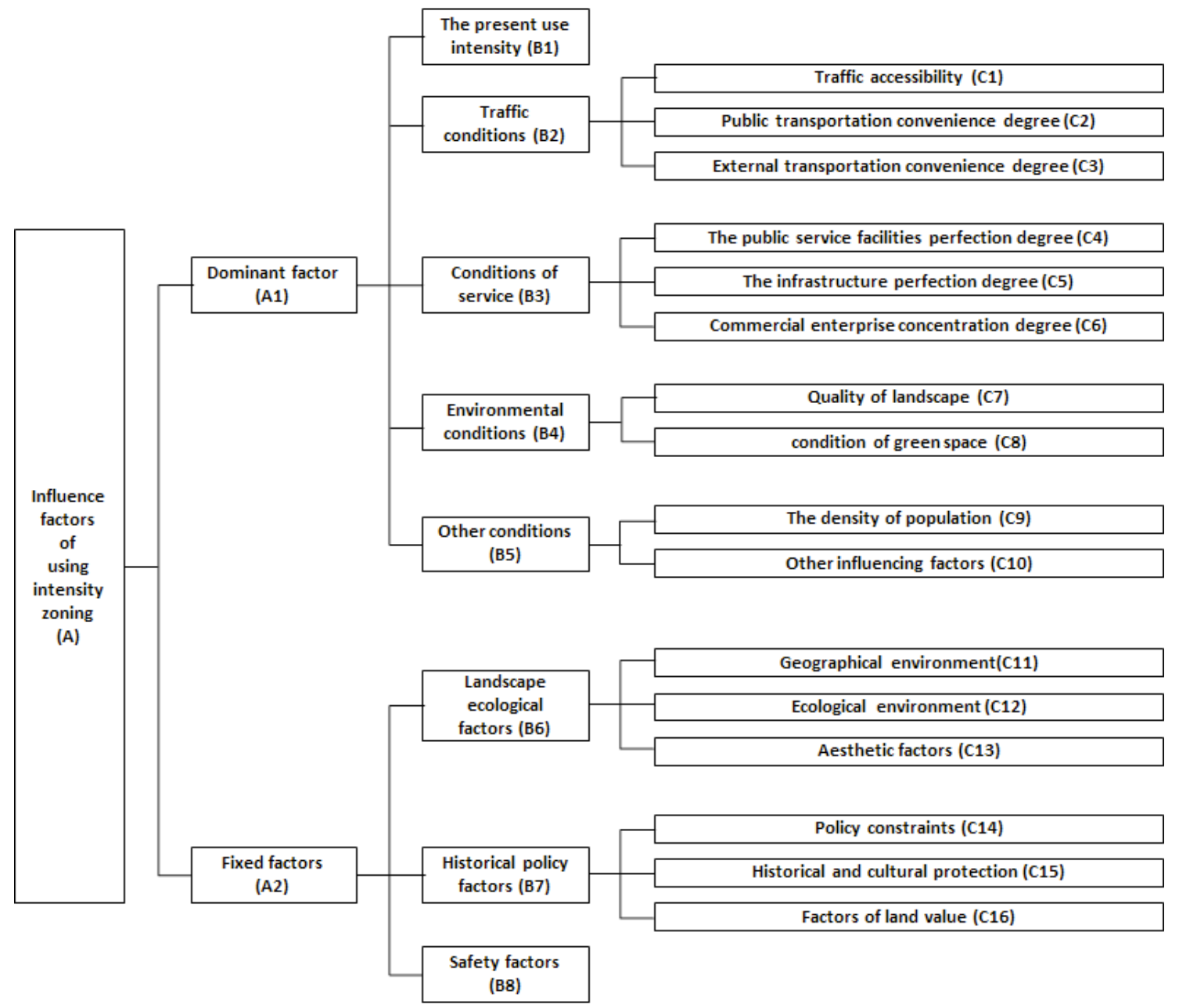

Fig. (2). Influence factors in the land use intensity.

target layer. Secondly, analyze the different kinds of influence factors of land use intensity zoning on unit level, combine all kinds of factors systematically, and then form the comprehensive factor layer and basic factor layer to link up with the target layer and construct the complete hierarchical structure. Finally, through the method of fuzzy quantification about the qualitative indicators, and through certain rules and expert evaluation, to endow the factor layer on various levels with a certain numerical value by expert scoring, construct the weight of judgment matrix calculation of the target level, and so on.

Using the method of AHP model to express the "unit intensity zoning impact factor evaluation" system, the whole model can be divided into four levels and two steps. "Four levels" are the total target level (T), total factor level (A), sub factors level (B) and index level (C). The total target level is the establishment of land use intensity levels; the branch target level is the establishment of the standard of distribution of each unit based on dominant influence factors and modifying influence factors; the factors' level includes the present situation of land use intensity and traffic conditions, service conditions, environmental conditions and other conditions; the index layer is composed of elements of all kinds of factors. "Two steps" is first classifying the basic factors through the weight of the basic factors level. The second step, calculate the weight of each unit on each factor level, get the weight of each unit under the dominant influence factors and modifying influence factors, and establish a basic intensity zoning and modifying zoning, and finally determine the ultimate strength zoning of land use [9].

\subsection{The Determination of the Influence Factors on Land use Intensity Zoning, and the Establishment of Its Hier- archical Structure}

Using the management unit as the spatial analysis unit, the choice of all kinds of factors and its impacts on the floor area ratio is directly reflected in the unit's overall comprehensive influence. According to land economic input-output theory, the key factors affecting planning floor area ratio depends on the transfer fund of the land, within the management unit, determine the land use intensity in different plots under the premise of the confirmation of the reference floor area ratio, according to the different benefit of traffic conditions, environmental conditions and service conditions in different plots and the protection requirements of the famous historical and cultural city. So we limit the use intensity of those lands that are given higher use intensity [10].

There are many factors that influence the use intensity level of unit land, and the relationship between various factors influence and restrict each other. The factors, which 
have a large influence, wide coverage, and reflect the heterogeneity and comparability between each unit, should be determined as the evaluation value. According to the characteristics of drafting regulatory plan about the small and medium-sized city in Guanzhong area and the unit division situation, and through analysis of unit area and their own conditions, we can establish three hierarchy analytic structure for division level evaluation of unit use intensity, that are total factor level (A), sub factors level (B) and index level (C) [11].

Generally, the main factors affecting land use intensity are divided into two categories: the dominant factors (A1) and the modifying factors (A2). The dominant factors refer to the factors which have impacts on the city construction, with universal influence, and major ones are economic factors, including the public service facilities perfection degree, the infrastructure perfection degree, commercial enterprise concentration degree, traffic access degree, public transportation convenience degree, external transportation convenience degree, condition of green space, landscape quality, the density of population and the concentration degree of business and administrative office. Modifying factors refer to the affect factors to some specific regions, which are not universal effect to the whole city. It mainly includes the restrictive factors like the ecological environment, urban planning and decision-making, policy factors, land price, and so on.

\subsection{The Determination of Total Amount of the Land Use Intensity Zoning on Management Unit Level}

Under the specific overall planning, the total floor area ratio should be planned according to the total construction and total population of a certain urban construction area, and then according to all kinds of per capita area indices and indices representing measured using intensity or residential environment indices (such as standards of construction land per capita, the per capita green area, the per capita traffic square area, building density and building height, the ratio of green space and so on), based on the aesthetic factors target of the city center and the ecological environment capacity, the control allocation principle of land use intensity zoning can be obtained based on the aesthetic factors target of the city center and the ecological environment capacity [12].

Regard $S$ as the total land area $\left(\mathrm{m}^{2}\right), \bar{F}$ as the total average floor area ratio, then the total development and construction (DC) of the whole city center can be determined by the following formula:

$D C_{\text {top limit }}=S_{\text {total }} \cdot \bar{F}_{\text {total }}$

Based on the determination of the total city construction Intensity, we can redistribute the amount of the space on unit level.

Assume $S_{i}$ as the land area of a management unit, $\bar{F}_{i}$ as the average plot ratio of unit planning, then the lower limit of the development and construction can be determined by the following formula:

$$
D C_{\text {lower limit }}=\sum_{i}\left(S_{\mathrm{i}} \cdot \bar{F}_{\mathrm{i}}\right)
$$

The average floor area ratio of unit $\left(\bar{F}_{i}\right)$ is comprehensively obtained according to the economic factors such as the present floor area ratio, the land development costs and the development sales revenue, relocation costs, and so on [13].

The average floor area ratio $\left(\bar{F}_{i}\right)$ is comprehensively obtained according to the economic factors of unit $i$, such as the present floor area ratio, the land development costs and the development sales revenue relocation costs, and so on [13].

\subsection{Factors Classification Assignment System and the Method to Determine the Weighing Values of Assessment}

Under normal circumstances, when using the linear evaluation model to seek a comprehensive evaluation of the final results of the evaluation, we use the linear superposition mapping model (also called weighted cumulative model) to evaluate it. Through the analysis above, we will obtain the corresponding weight and the evaluation value of the evaluation factors of the prior determined factors. After linear weighted superposition of multi-factors, the evaluation result comes to the hierarchical evaluation value of each unit under economic factors, that is:

$N=\sum_{i=1}^{n}\left(\omega_{i} \cdot N_{i}\right)$

$N$ is the level evaluation value, $n$ is the number of factors, $\omega_{\imath}$ is the evaluation weights of the number i factor, $N_{i}$ is the score of the number i factor.

When calculating the weight value, because that the most index in the index system have the ambiguity and uncertainty, evaluation takes several gray, fuzzy judgment methods which unified converted to nine rating points system. In sorting calculation, first compare the two factors, and constitute a judgment matrix, then calculate the largest eigenvalue and finally eigenvector of the judgment matrix, and make the judgment quantitatively according to a certain ratio scaling.

\begin{tabular}{c|cccc}
$A$ & $B_{1}$ & $\mathrm{~B}_{2}$ & $\cdots$ & $B_{n}$ \\
\hline$B_{1}$ & $b_{11}$ & $b_{12}$ & $\cdots$ & $b_{1 n}$ \\
$\mathrm{~B}_{2}$ & $b_{21}$ & $b_{22}$ & $\cdots$ & $b_{2 n}$ \\
$\cdots$ & $\cdots$ & $\cdots$ & $\cdots$ & $\cdots$ \\
$B_{n}$ & $b_{n 1}$ & $b_{n 2}$ & $\cdots$ & $b_{n n}$
\end{tabular}

$\mathrm{A}$ is an element on the top level.

If $\mathrm{Bi}$ and $\mathrm{Bj}$ are equally important, then take $\mathrm{Bij}=1$.

If $\mathrm{Bi}$ is little more important $\mathrm{Bj}$, then take $\mathrm{Bij}=3$.

If $\mathrm{Bi}$ is obviously more important $\mathrm{Bj}$, then take $\mathrm{Bij}=5$.

If $\mathrm{Bi}$ and $\mathrm{Bj}$ are strongly significant, then $\mathrm{Bij}=7$.

If $\mathrm{Bi}$ and $\mathrm{Bj}$ are extremely important, then $\mathrm{Bij}=9$.

When compared with each other, 1, 3, 5, 7, 9 indicate the degree of importance, 2,4,6,8 are the value between the two relative important points [15].

\section{ANALYSIS OF CITY LAND USE STRENGTH DIVI- SION ON SHAANXI PUCHENG}

\subsection{Weight of Factors for Each Unit under the Dominant Factor - the Basic Model}

According to principles of the city development and city planning economy, and because of the scarcity of land re- 
Table 2. The dominant factor weight value table.

\begin{tabular}{|c|c|c|c|c|c|c|c|}
\hline \multicolumn{2}{|c|}{ Basic Influencing Factors A1 } & B1 & B2 & B3 & B4 & B5 \\
\cline { 2 - 7 } & Strength use of the & $\begin{array}{c}\text { Traffic } \\
\text { Condition }\end{array}$ & $\begin{array}{c}\text { Service } \\
\text { Condition }\end{array}$ & $\begin{array}{c}\text { Environmental } \\
\text { Condition }\end{array}$ & Other Condition & Weight Value \\
\hline \hline B1 & $\begin{array}{c}\text { The current situation of } \\
\text { the strength use }\end{array}$ & 1 & 2 & 3 & 3 & 0.400 \\
\hline B2 & Traffic condition & $1 / 2$ & 1 & 2 & 3 & 2 \\
\hline B3 & Service condition & $1 / 3$ & $1 / 2$ & 1 & $1 / 3$ & 3 \\
\hline B4 & Environmental condition & $1 / 3$ & $1 / 3$ & 3 & 1 & 0.118 \\
\hline B5 & Other condition & $1 / 4$ & $1 / 2$ & 2 & 3 & 0.110 \\
\hline
\end{tabular}

Note: The consistency checking: $\mathrm{CR}>0.10$

Table 3. The weight of each unit under the dominant factors.

\begin{tabular}{|c|c|c|c|c|c|c|}
\hline $\begin{array}{l}\text { B layer } \\
\text { Weight } \\
C \text { Layer } \\
\text { Weight }\end{array}$ & $\begin{array}{l}\text { The Current Situa- } \\
\text { tion of the Strength } \\
\text { use B1 } 0.400\end{array}$ & $\begin{array}{l}\text { Traffic Condition } \\
\text { B2 } 0.243\end{array}$ & $\begin{array}{l}\text { Service Condition } \\
\text { B3 0.118 }\end{array}$ & $\begin{array}{c}\text { Environmental } \\
\text { Condition B4 0.110 }\end{array}$ & $\begin{array}{c}\text { Other Condition B5 } \\
\mathbf{0 . 1 2 9}\end{array}$ & Weight Value \\
\hline ZX-01 & 2 & 1.1 & 1.35 & 1 & 3 & 1.72 \\
\hline ZX-03 & 3 & 1.6 & 2.7 & 2.4 & 2 & 2.43 \\
\hline ZX-04 & 2 & 1.4 & 1.3 & 1.45 & 3 & 1.84 \\
\hline ZX-05 & 3 & 2 & 2.7 & 2.4 & 4 & 2.78 \\
\hline ZX-06 & 1 & 2 & 2 & 2.6 & 4 & 1.92 \\
\hline PD-01 & 1 & 1.55 & 2.35 & 1.6 & 2 & 1.49 \\
\hline
\end{tabular}

sources, especially for the developed city land, there is a relationship between supply and demand among land, such relationship is rather special. The rent price of the land, which decides the value of city land can also, decides the property and construction of land. But the location of city land is the decisive factor of city land price. Accessibility of transportation facilities, as well as the city infrastructure conditions is important factors that influence the land location. To cities of a certain scale, it has an economic rule of land, namely the rule of land value.

According to the actual situation in Pucheng, the dominant factors weight value calculations are listed in the following table (Table 2).

Through comparing the dominant factors to each other and establishing judgment matrix, to calculate the weight of the present land use intensity is 0.400 , the weight of traffic conditions is 0.243 , the weight of service conditions is 0.118 , the weight of environmental conditions is 0.110 , and the weight of the other factors is 0.129 .
There are five influence factors in this basic level evaluation, which are the present situation of recent land use intensity, traffic conditions, service conditions and the other conditions. The classification assignment and weight of Pucheng in the following table (Table 3).

Through the data integration, besides no strength used of public open space, the downtown land use intensity will be divided into four zones (Fig. 3). ZX - 05, 03, 06 are of intensity level 1, ZX - 04 is of intensity level 2, ZX - 02, ZX - 01, PN - 01 are of intensity level 3, PD - 01, PN - 02 are of intensity level 4 (Fig. 3).

\subsection{Modifying Factors Analysis and Modifying Model of Land Use Intensity}

Modify the basic model, namely modify the unit which have modifying factors, and on the contrary not to modify. First of all, calculate modifying factors alone to get evaluation value of each units, and then composite the basic evaluation value. These modifying factors are the restricted conditions, which are in inverse proportion with land use intensity. 


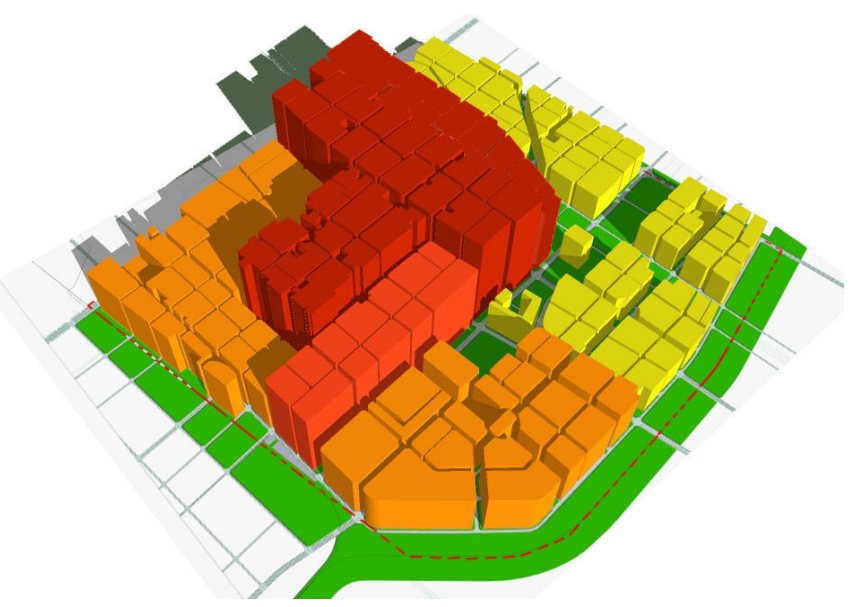

Fig. (3). Schematic diagram of intensity zoning basic model.

\subsubsection{Landscape Ecological Factors B6}

Combine geographical environment, ecological environment and aesthetic factors unit, calculate the weight average according to the table assignment, obtained the result of each unit level, as the value under the influence of landscape ecology.

Here it comes to levels of land use intensity value under the influence of landscape ecology. The conclusion is that B6 (ZX-01) evaluation value is 1.1. B6 (ZX-02) evaluation value is 1.1. B6 (ZX-03) evaluation value is 0.55 . B6 ( $Z X-$ $04)$ evaluation value is 1.1 . $\mathrm{B} 6(\mathrm{ZX}-05)$ evaluation value is 2.2. $\mathrm{B} 6(\mathrm{ZX}-06)$ evaluation value is 2.65 . $\mathrm{B} 6(\mathrm{PN}-01)$ the evaluation value is 2.1). $\mathrm{B} 6$ ( $\mathrm{PN}-02)$ evaluation value is 2.1 . B6 (PD-01) evaluation value is 1.55.

Based on modifying factor weight and classification assignment combination weights and the reference model modifying under landscape ecological mainly concentrated in $Z X-06, P D-01, P N-01, P N-02$, to modify the four units, ZX - 06 modified to intensity level 1, PD - 01, PN - 02 modified to intensity level 3 , the PN - 01 modified to intensity level 2 (Table 4).

\subsubsection{Historical Policy B 7}

Calculate the average weight according to the table above with policy constraints, protection of historical cultural rel- ics, and price factor, and obtain the data results of each unit as a value affected by the historical policy.

Get use intensity value of each land based on history and policy factors, concluding that $\mathrm{B} 7(\mathrm{ZX}-01)$ value is 0.55 . $\mathrm{B} 7(\mathrm{ZX}-02)$ value is $0.55 . \mathrm{B} 7(\mathrm{ZX}-03)$ value is $0 . \mathrm{B} 7(\mathrm{ZX}$ - 04) value is 0.55 . $\mathrm{B} 7(\mathrm{ZX}-05)$ value is 0.39 . $\mathrm{B} 7(\mathrm{ZX}-06)$ value is 1.38. $\mathrm{B} 7(\mathrm{PN}-01)$ value is 2.1 and $\mathrm{B} 7(\mathrm{PN}-02)$ value is 2.1 .

Considering modified factors weight and classification assignment weights, factors of modifying based on the landscape ecological reference model are mainly concentrated in PD - 01, PN - 01, PN - 02 three units, among which PD-01 and $\mathrm{PN}-02$ are modified as level 2, and $\mathrm{PN}-01$ are modified as level 1.

Because $\mathrm{PN}-01$ is defined as sub-center, the administrative center in the future of Pucheng, the construction should not be the most intensity areas in the city. So the land strength use of PN - 01 is still located on level 2 (Table 5).

\subsubsection{Safety Factors B8}

Engineering suitability evaluation of urban land should be mainly regarded as the standard, presenting in: (1) terrain slope, (2) soil bearing capacity, (3) groundwater level, (4) flood years limit, (5) gulley, landslide, slide, and other undesirable geological phenomena.

The urban construction land within the central area is divided into three categories: The first category land whose slope is less than $5 \%$, conforms to the requirements of most of the construction, and meets the requirements of the building foundation bearing capacity and embedding depth of architectural of water table, without the once-in-a-century flooding danger and bad geological phenomenon. The second category land, whose slope is above $5 \%$ and below $15 \%$, needs larger earthwork, and its foundation needs to take some artificial reinforcement measures, needs artificial reinforcement measures on ground, or reducing the water table or drainage measure when constructing, it belong to mild flood submerged area requiring flood prevention measure, and there exists slightly bad geological phenomenon requiring project preparation measures. The third category land, whose slope is above $15 \%$ and below $30 \%$, is hard to construct buildings, frequent flooding and serious geological phenomenon.

Table 4. Classification assignment of landscape ecological factors.

\begin{tabular}{|c|c|c|c|c|}
\hline Unit Number & Evaluation Factor & Attribute Classification & Evaluation Value & Modify the Weight Value \\
\hline \multirow{2}{*}{$\mathrm{C} 11$} & \multirow{2}{*}{ Regional environment } & Small intensity of transformation & 0 & \multirow{2}{*}{0.45} \\
\hline & & Big intensity of transformation & 1 & \\
\hline $\mathrm{C} 12$ & Ecological environment & - & - & - \\
\hline \multirow{4}{*}{$\mathrm{C} 13$} & \multirow{4}{*}{ Aesthetic factor } & High-level development control area & 1 & \multirow{4}{*}{0.55} \\
\hline & & General area & 2 & \\
\hline & & Important area & 3 & \\
\hline & & Guide the high-level development area & 4 & \\
\hline
\end{tabular}

Note: modified the land use intensity in which exist modifying factors 
Table 5. History and policy factors classification assignment.

\begin{tabular}{|c|c|c|c|c|}
\hline Unit Number & Evaluation Factor & Attribute Classification & Evaluation Value & Weight Value \\
\hline \multirow{2}{*}{$\mathrm{C} 14$} & \multirow{2}{*}{ Policy constraint } & Key construction area & General construction area & \multirow{2}{*}{0.45} \\
\hline & & Dong Xin Area & 1 & \\
\hline \multirow{3}{*}{$\mathrm{C} 15$} & \multirow{3}{*}{$\begin{array}{l}\text { Protection of historical cul- } \\
\text { tural relics }\end{array}$} & Traditional Chinese style & 1 & \multirow{3}{*}{0.55} \\
\hline & & Modern Chinese style & 2 & \\
\hline & & Modern style & 3 & \\
\hline $\mathrm{C} 16$ & Price factor & - & - & -- \\
\hline
\end{tabular}

Table 6. Classification model of urban land use intensity zoning of each unit.

\begin{tabular}{|c|c|c|}
\hline $\begin{array}{l}\text { Strength Characteristics } \\
\text { of Each District }\end{array}$ & $\begin{array}{l}\text { Management } \\
\text { Unit }\end{array}$ & Features \\
\hline $\begin{array}{l}\text { The intensity of the first } \\
\text { district }\end{array}$ & $\mathrm{ZX}-05,06, \mathrm{PN}-02$ & $\begin{array}{l}\text { It is located in the central area with excellent traffic location and beautiful environment. Most of the } \\
\text { area is dominated by residential, commercial and warehousing logistics land. }\end{array}$ \\
\hline $\begin{array}{l}\text { The intensity of the second } \\
\text { district }\end{array}$ & $\begin{array}{l}\text { ZX-04, PN-01, } \\
\text { PD-01 }\end{array}$ & $\begin{array}{l}\text { It mainly includes the new urban development zone, city Administration center and research design } \\
\text { education center, with an excellent environment and a secondary traffic location. }\end{array}$ \\
\hline $\begin{array}{l}\text { The intensity of the third } \\
\text { district }\end{array}$ & $Z X-01,02$ & $\begin{array}{l}\text { At the edge of the city center area, the traffic condition is slightly inconvenient and green landscape } \\
\text { is less. It is dot-oriented and belongs to the style of coordination area. }\end{array}$ \\
\hline $\begin{array}{l}\text { The intensity of the fourth } \\
\text { district }\end{array}$ & ZX-03 & $\begin{array}{l}\text { It is located the scope of the old city and belongs to the key history and culture reservation district. It } \\
\text { has strict requirements for development and construction. }\end{array}$ \\
\hline $\begin{array}{l}\text { Ecological landscape con- } \\
\text { trol district }\end{array}$ & Central urban area & $\begin{array}{l}\text { It mainly refers to the urban public green landscape and the isolation green belt set with special } \\
\text { requirements, urban public open space such as city recreation square. }\end{array}$ \\
\hline
\end{tabular}

Based on the above safety evaluation of urban construction, land use intensity of different units could be inferred. Construction of units in the central urban area is relatively homogenous and balance, poor geological phenomenon.

\subsection{Final Assessment of the Strength Division}

Based on GIS (Geography Information System) platform, the weighted stacking method is employed to combine the dominant factors and modifying factors to establish a respectively the basic level model is modified according to the development characteristics of the small and medium-sized cities in Guanzhong finally forming the use intensity zoning model. To build the intensity of use by four level model in Pucheng, i.e. district one to district four, use intensity decreases one by one [16].

\subsubsection{Strength Characteristics of Each District (Table 6,} Fig. 4)

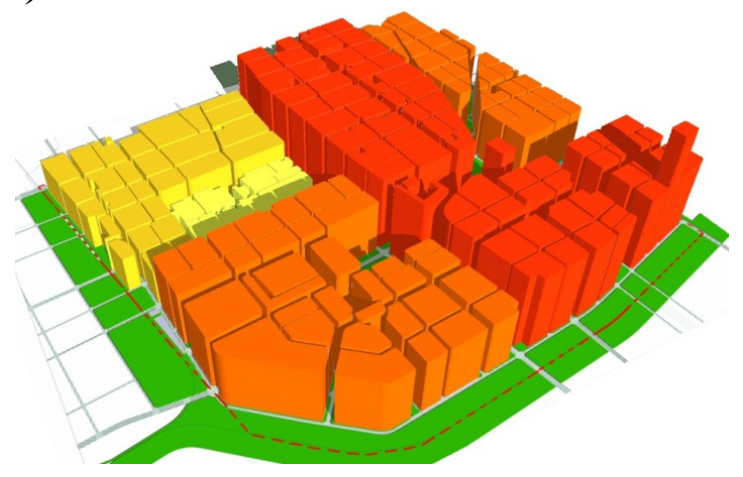

Fig. (4). Management unit intensity of land use zoning plan.

\subsubsection{Allocation Methods of Development and Construc- tion}

Total amount of construction should be reasonably allocated within the scope of the intensity zoning, according to the population distribution structure and the characteristics of land use determined the land use layout of regulatory detailed planning, so as to measure the intensity zoning of population density. Combined with population density distribution and levels of construction intensity division, we can assign intensity zoning of all levels of total amount of residential and other construction land, according to the principle of balance between supply and demand.

After level model of zoning is set up, identified reference floor area ratio of each level of land use. Based on the reference, guide the floor area ratio of neighborhood and land, and determine the land floor area ratio of lands with character, combined with "Shaanxi Province urban planning technical regulations" (Table 7).

\section{CONCLUSION}

When establishing the level of distribution intensity, analysis of various influence factors, which affect land use intensity in the future, could be carried out to get the results of their strength use and importance degree. Through expert scoring and database to establish the weights of each factor, taking fuzzy judgment matrix approach to sort out the various factors. Using GIS platform to build basic model and modified model of unit division level.

Intensity zoning research is based on the value from the top to down-----this scope of the study is a relatively new 
Table 7. Floor area ratio of reference management.

\begin{tabular}{|c|c|c|c|c|c|}
\hline Index type & Land use Type & $\begin{array}{l}\text { Intensity } \\
\text { District } 1\end{array}$ & $\begin{array}{l}\text { Intensity } \\
\text { District } 2\end{array}$ & $\begin{array}{l}\text { Intensity } \\
\text { District } 3\end{array}$ & $\begin{array}{l}\text { Intensity } \\
\text { District } 4\end{array}$ \\
\hline \multirow{5}{*}{$\begin{array}{l}\text { Reference floor } \\
\text { area ratio }\end{array}$} & Residential land (without primary and secondary school) & 3.2 & 2.5 & 2.0 & 1.5 \\
\hline & $\begin{array}{l}\text { Business, financial land (including trade, services, and com- } \\
\text { mercial office building) }\end{array}$ & 4.0 & 3.5 & 3.0 & 2.0 \\
\hline & Office land (hotel, and office mainly for administrative) & 4.0 & 3.5 & 3.0 & 2.0 \\
\hline & $\begin{array}{c}\text { Other public facilities (including primary and middle } \\
\text { schools, culture, sport, education, health care and other pub- } \\
\text { lic welfare service facilities) }\end{array}$ & 2.0 & 1.7 & 1.4 & 1.1 \\
\hline & Industry land (general factory), storage land & - & - & 1.5 & 1.1 \\
\hline \multicolumn{2}{|r|}{ Management unit } & $\begin{array}{c}\text { ZX-05 ZX-06 } \\
\text { PN-02 }\end{array}$ & $\begin{array}{l}\text { ZX-04 } \\
\text { PN-01 } \\
\text { PD-01 }\end{array}$ & $\begin{array}{l}\text { ZX-01 } \\
\text { ZX-02 }\end{array}$ & ZX-03 \\
\hline
\end{tabular}

Note: (1) The rated Floor area ratio should be combined with land use construction conditions to coordinate reference floor area ratio according to the coefficient of floor area ratio. (2) For construction land with floor area ratio that is not clearly stipulated in the table, the construction intensity can be reference nearby, for instance, the first and the second district can refer to the third one.

direction. The study was multidisciplinary, with endless depth and breadth. Faced with such a complex giant system, there are lot imperfections to be reconsidered due to the lack of various disciplines of learning and understanding as well as the constraints of data collection, time and so on. Thus, the research and the method remains to be further explored. However, the original intent of this research is to be a starting point, with which do more modifying and researches in the future study and work.

\section{CONFLICT OF INTEREST}

The authors confirm that this article content has no conflict of interest.

\section{ACKNOWLEDGEMENTS}

The work is supported by Shaanxi Province Social Science Fund Project (2014D39), 2014 Science and Technology Project Plan of Housing and Urban-Rural Development-soft Science Research Project (Project No. 2014-R2-026), Grant Project Construction Funds for Science and Technology of 2014 Shaanxi Province Housing and Urban Rural Construction Bureau -- Soft Science (2014-R80).

\section{REFERENCE}

[1] Y. Wei, J. Zhu, and S. Yang, "Innovating Regulatory Planning with Examples of American Zoning Regulations," Planners, vol. 26, no. 10, pp. 113-118, 2010.

[2] Economics Theory of Urban development and planning. China Higher Education Press, CHEP: Zhao Min, Tao Xiaoma, 2001.

[3] Modern Urban Planning Theory. : China Architecture \& Building Press: Sun Shiwen 2007.
[4] H. Yu, "Study on Method of Regulatory Detailed Planning," Master degree of engineering, Tsinghua University, 2007.

[5] D. Wei, C. Rong, and 1. Xia, "Regulatory Detailed Planning Practice of Hierarchical Control," - in Beijing, Chengdu and Shanghai, for example. Urban Planning Forum, pp.276-279, 2008.

[6] X. Hu, and G. Shen, "Reasonable Dividing Elements and the Applications of the," "Planning Unit" - Luoyang. Urban and Rural Planning, pp.40-41, 2010.

[7] K. Yao, "Exploration and Practice of Regulatory Unit Planning in Shanghai," Planning Administration, vol. 31, no. 8, pp. 52-57, 2007.

[8] Q. Shen, H. Liu, and R. Chen, "Tiered FAR Management," Planners, no. 7, pp. 74-78, 2013.

[9] Y. Yao, "Methods of Urban Development Intensity Zoning, Chengdu," The Harmonious City Planning -- China's Urban Planning Conference Proceedings, pp. 1947-1951, 2007.

[10] B. Zhou, H. Bao, and B. Peng, "Evaluation on Exploitative Intensity of Land Resources in the Yangtze River Delta Regin," Scientia Geographica Sinica, vol. 20, no.3, pp. 218-223, 2000.

[11] D. Yao, Y. Hu, F. Zhang, Z. Wang, W. Zhou, "Research of the Land Developing Intensity Evaluation of Hainan Province," Journal of Hebei Agricultural Science, vol.12, no.1, pp. 86-87, 2008.

[12]Q. Song, "Macroeconomic Regulation and Quantitative Solution of FAR. City Planning Review," pp. 21-23, 1996.

[13] "Development Capacity of the old -town Renewal Determined by GIS--A Case Study of Old-town Renewal in Nanyang City," Journal of Chongqing Jianzhu University, vol. 27, no.6, pp. 6-11, 2005.

[14] Hejiang, Shi Xiaoli, Lv Min etc. "Economic Evaluation Based Model of Regulatory Detailed Planning Development Strength," China Urban Planning Conference Proceedings, 2010.

[15] "Comprehensive Evaluation Method of Green Residential and Design Criteria," China Architecture \& Building Press: Liu Qibo, Zhou Ruoqi, 2006.

[16] Based on GIS Dynamic Change of Land Use and Land ecological security research in Guanzhong region. China Environmental Science Press: Mo Hongwei, Ren Zhiyuan, 2011.

(C) Quanhua et al.; Licensee Bentham Open.

This is an open access article licensed under the terms of the Creative Commons Attribution Non-Commercial License (http://creativecommons.org/licenses/by-nc/3.0/) which permits unrestricted, non-commercial use, distribution and reproduction in any medium, provided the work is properly cited. 